\title{
Application of Data Envelopment Analysis to Efficiency Evaluation on R\&D Input and Output
}

\author{
Rongping $\mathrm{Li}^{1, *}$, Yuanjie $\mathrm{Li}^{1}$ and Zheng $\mathrm{Cui}^{2}$
}

${ }^{I}$ School of Economics \& Management, Hebei University of Science and Technology, Shijiazhuang, China; ${ }^{2}$ School of Humanity and Law, Hebei University of Science and Technology, Shijiazhuang, China

\begin{abstract}
As the role of economic development, science and technology got more and more get people's attention, the efficiency of R\&D input also gradually becomes the focus of political and academic discussion. This paper expounds the principle of data envelopment method, and then builds an evaluation index system of the efficiency in R\&D input and output of the research and development institutions (R\&D institutions) based on DEA method, after reading related literatures at home and abroad. Using related data of Chinese 30 provinces (lack of Tibet) R\&D institutions to verify the established model, namely, measuring and analyzing output efficiency, input redundancy and output deficiency of Regional $R \& D$ institutions in China $R \& D$ input, and concluding the regional characteristics of R\&D activities. The evaluation Index system of regional R\&D institutions of our country not only has important guiding significance to the efficiency evaluation, and the results of the validation research also is of great significance to clear R\&D institutions development goals, improve configuration of $R \& D$ resources, and improve the level of their scientific research ability.
\end{abstract}

Keywords: Conclusions and recommendations, expenditure structure, investment in R\&D, optimized measuring, utility function.

\section{INTRODUCTION}

R\&D activities of Research and Development Institutions (R\&D Institutions) occupy an important position in the regional R\&D activities, not only can provide theoretical basis and support for the development of national science and technology, also can be used for regional development of science and technology to provide a large number of scientific and technological personnel, and promote the transformation and application of research results. Therefore, the quality and $R \& D$ activities of $R \& D$ Institutions, the rationality of the allocation of R\&D resources, and the level of utilization efficiency are not an only important way to promote the progress of science and technology, but also the fundamental guarantee and content for raising the regional independent innovation ability, and realizing the sustainable development of economy. This paper adopts DEA method to scientifically measure input and output efficiency of R\&D Institutions in different provinces, which explains the relationship between R\&D investment scale and the input structure, output efficiency, and puts forward important reference for pinpointing development goal of regional R\&D Institutions, and improving the level of their scientific research ability and allocation of $R \& D$ resources [1-3].

\section{DEA MODEL}

DEA is a nonparametric method of relative efficiency evaluation suitable for multiple input and multiple output complex system analysis, proposed by the famous American operations research expert - A. Chames, W.W. Cooper, E. Rhodes in 1978.

\section{1. $C^{2} R$ Model of DEA}

Assume that there are $\mathrm{n}$ units or decisions making units (DMU), each decision unit $\mathrm{DMU}_{j}(j=1,2, \ldots, m)$ has $\mathrm{m}$ kinds of inputs $\mathrm{X}_{i j}(i=1,2, \ldots, m), \mathrm{s}$ kinds of outputs $\mathrm{Y}_{k j}(k=1,2, \ldots$, $s)$, so the efficiency of decision making units such as (1):

$h_{j}=\sum_{k=1}^{s} u_{k} y_{k j} / \sum_{i=1}^{m} v_{i} x_{i j} \quad j=1,2, \cdots, n$

In the equation $(1), v_{i}(i=1,2, \ldots, m)$ and $\mathrm{u}_{k}(k=1,2, \ldots, s)$ are the input weight of the type $i$ and the output weight of type $k$. Normally, the bigger the $\mathrm{h}_{j 0}$, the smaller of output for a given input. In this way, we can change the weight coefficient to maximize the $h_{j 0}$. and construct the $C^{2} R$ model, such as equation (2):

$$
\left\{\begin{array}{l}
\max h_{j 0}=\sum_{k=1}^{s} u_{k} y_{k j 0} / \sum_{i=1}^{m} v_{i} x_{i j 0} \\
\text { s.t. } \sum_{k=1}^{s} u_{k} y_{k j} / \sum_{i=1}^{m} v_{i} x_{i j} \leq 1 \quad j=1,2, \cdots, n \\
v_{i}=\left(v_{1}, v_{2}, \cdots, v_{m}\right)^{T} \geq 0 \quad i=1,2, \cdots, m \\
u_{k}=\left(u_{1}, u_{2}, \cdots, u_{s}\right)^{T} \geq 0 \quad k=1,2, \cdots, s
\end{array}\right.
$$

$\mathrm{C}^{2} \mathrm{R}$ model solved by its dual linear programming model, such as equation (3): 


$$
\left(C^{2} R\right)\left\{\begin{array}{l}
\min \theta \\
\text { s.t. } \sum_{j=1}^{n} \lambda_{j} x_{j}+s^{-}=\theta x_{0} \\
\sum_{j=1}^{n} \lambda_{j} y_{j}-s^{+}=y_{0} \\
\lambda_{j} \geq 0, j=1,2, \ldots, n \\
\theta i s \text { unconstrained, } s^{+} \geq 0, s^{-} \geq 0
\end{array}\right.
$$

Where, $s^{+}, s^{-}$are slack variables.

The economic meanings of model: When $\theta=1$, and $s^{+}=s^{-}=0, \mathrm{DMU}_{j 0}$ is DEA efficient, as well as effective on technology and effective on scale. When $\theta<1$, the $\mathrm{DMU}_{j 0}$ is non-DEA effective, at this point, not directly according to the size of the $\theta$, we don't determine decision unit is invalid due to technology non-effective, or the scale noneffective.

\subsection{BC $^{2}$ Model of DEA}

$\mathrm{BC}^{2}$ model is the improvement of the $\mathrm{C}^{2} \mathrm{R}$ model, which gives constraints that the sum of weight coefficients equals to 1 , such as equation (4):

$$
\left(B C^{2}\right)\left\{\begin{array}{l}
\min \sigma \\
\text { s.t. } \sum_{j=1}^{n} \kappa_{j} x_{j}+s^{-}=\sigma x_{0} \\
\sum_{j=1}^{n} \kappa_{j} y_{j}-s^{+}=y_{0} \\
\sum_{j=1}^{n} \kappa_{j}=1 \\
\kappa_{j} \geq 0, j=1,2, \ldots, n \\
\theta \text { is unconstrained, } s^{+} \geq 0, s^{-} \geq 0
\end{array}\right.
$$

When $\sigma=1$, the $\mathrm{DMU}_{j 0}$ is technology effective, otherwise, $\mathrm{DMU}_{j 0}$ is technology non-effective.

When $\delta=1$, the $\mathrm{DMU}_{j 0}$ is scale effective, at this time, the input $\left(\mathrm{DMU}_{j 0}\right)$ is in the best state of constant returns to scale; When $\delta<1$ and $\sum_{j=1}^{n} \lambda_{j}<1$, the $\mathrm{DMU}_{j 0}$ is scale noneffective, and under the period of increasing returns to scale; When $\delta<1$ and $\sum_{j=1}^{n} \lambda_{j}>1$, the $\mathrm{DMU}^{j 0}$ is scale non-effective, and in the stage of scale of decreasing returns.

\subsection{Input Redundancy and Output Deficiency}

When $\mathrm{DMU}_{j 0}$ ' relative efficiency $\theta=\theta^{*}<1$, it's the technology non-effective; assuming $\mathrm{DMU}_{j 0}$ target score of effective of input and output is $x *_{j 0} 、 y *_{j 0}$, so the input redundancy is $\Delta x_{j 0}=x_{j 0}-x^{*}{ }_{j 0}$ and the output deficiency is
$\Delta y_{j 0}=y_{j 0}^{*}-y_{j 0}$, which means that under the condition of constant output level $y_{j 0}$, input indicators reduce the amount of $\triangle x_{0}$, or under the condition of constant input levels $x_{j 0}$, output index increase the amount of $\triangle y_{0}$ [4-6].

\section{THE CONSTRUCTION OF EVALUATION IN- DEX SYSTEM AND DATA}

\subsection{The Construction of Evaluation Index System}

R\&D activities refer to the systematic and creative work to increase the amount of knowledge (including aspects of human culture and social knowledge), and use this knowledge to create new applications in the field of science and technology. In R\&D activities, input including people, goods, and other resources, and mainly refers to the R\&D funds input and personnel input; output comprise the patent, academic papers, works and the number of the national or industry standards formed, and other direct scientific and technological achievements, as well as the economic benefits from the development of social and economic promoted by $\mathrm{R} \& \mathrm{D}$ activities.

The efficiency of R\&D input and output refers to the utilization rate of the inputs in $R \& D$ activities relative to the output capacity. Through efficiency evaluation, we can explain the effect of R\&D input and output, analyze and reasonably judge the innovation ability of scientific and technological, and enhance the management performance of science and technology activities, to provide the basis for adjusting the development strategy of science and technology, optimizing the allocation of resources, improving the utilization rate of resources of science and technology [7-9].

Based on the connotation of efficiency of R\&D input and output, considering the principle of science, feasibility, guidance, and combining with the actual situation of R\&D activities of R\&D Institutions in China, this paper selects R\&D input and output efficiency evaluation indexes of R\&D Institutions from two aspects - input and output, such as Table $\mathbf{1 .}$

\subsection{Evaluation Caliber and Data Sources}

This article selects 30 provinces (lack of Tibet) as decision units in measuring of the efficiency of R\&D input and output. When collecting the raw data, considering the lag between input and output of R\&D activities is objective, lag period is 1-3 years usually, related degree the input and output indicators of delay 1 years is strongest by calculating, the strongest, so we make 1 year as lag period. Data from the "China Science and Technology Statistical Yearbook 2011".

\section{THE EMPIRICAL EVALUATION AND ANAL- YSIS}

Using $\mathrm{C}^{2} \mathrm{R}$ and $\mathrm{BC}^{2}$ model of DEA method to calculate the evaluation results of efficiency of R\&D input and output, insufficient input redundancy and output score from 2010 provincial cities' R\&D Institutions, such as in Table 2. 
Table 1. Evaluation indexes system of input and output efficiency of R\&D.

\begin{tabular}{|c|c|}
\hline Type & Specific Indicators \\
\hline \hline \multirow{3}{*}{ Input Index } & 1. R\&D Personnel (person) \\
\cline { 2 - 3 } & 2. Intramural Expenditure on R\&D (RMB one hundred million) \\
\hline \multirow{3}{*}{ Output Index } & 3. Scientific Papers Issued (piece) \\
\cline { 2 - 3 } & 4. Publication on Science and Technology (kind) \\
\cline { 2 - 3 } & 5. Number of Patent Applications Accepted (piece) \\
\cline { 2 - 3 } & 6. National or industry standards (term) \\
\hline
\end{tabular}

Table 2. Measurement results of R\&D input-output efficiency of the National R\&D Institutions in 2010.

\begin{tabular}{|c|c|c|c|c|c|c|c|c|c|c|}
\hline \multirow{2}{*}{ Provinces } & \multirow{2}{*}{ CSE } & \multirow{2}{*}{ CRS } & \multirow{2}{*}{ SE } & \multirow{2}{*}{ RTS } & \multicolumn{2}{|c|}{ Input Redundancy } & \multicolumn{4}{|c|}{ Output Deficiency } \\
\hline & & & & & RDP & IEST & SPI & PST & NPA & NIS \\
\hline Beijing & 0.586 & 1 & 0.586 & dec & 0 & 0 & 0 & 0 & 0 & 0 \\
\hline Tianjin & 0.398 & 0.625 & 0.637 & dec & 2304.25 & 6.81 & 772.7 & 0 & 1.05 & 0 \\
\hline Hebei & 0.268 & 0.303 & 0.885 & dec & 4017.65 & 17.6 & 0 & 27.51 & 0 & 12.9 \\
\hline Shanxi & 0.633 & 0.891 & 0.711 & dec & 1417.11 & 1.03 & 629.16 & 0 & 0 & 37.56 \\
\hline Inner Mongolia & 0.286 & 0.294 & 0.973 & dec & 2325.27 & 3.75 & 0 & 0 & 9.36 & 26.31 \\
\hline Liaoning & 0.593 & 1 & 0.593 & dec & 0 & 0 & 0 & 0 & 0 & 0 \\
\hline Jilin & 0.598 & 0.806 & 0.742 & dec & 1437.03 & 3.21 & 0 & 18.04 & 0 & 50.1 \\
\hline Heilongjiang & 0.339 & 0.435 & 0.78 & dec & 4040.5 & 12.96 & 0 & 0 & 103.9 & 25.26 \\
\hline Shanghai & 0.537 & 0.914 & 0.587 & dec & 1879.68 & 7.44 & 3765.39 & 175.44 & 0 & 178.55 \\
\hline Jiangsu & 0.473 & 0.713 & 0.663 & dec & 4474.37 & 19.06 & 125.63 & 111.69 & 0 & 127.66 \\
\hline Zhejiang & 0.874 & 1 & 0.874 & dec & 0 & 0 & 0 & 0 & 0 & 0 \\
\hline Anhui & 0.378 & 0.445 & 0.849 & dec & 3214.49 & 12.98 & 0 & 40.74 & 0 & 0.58 \\
\hline Fujian & 0.926 & 1 & 0.926 & dec & 0 & 0 & 0 & 0 & 0 & 0 \\
\hline Jiangxi & 0.387 & 0.399 & 0.97 & dec & 2334 & 4.49 & 0 & 8.41 & 62.18 & 7.54 \\
\hline Shandong & 0.613 & 1 & 0.613 & dec & 0 & 0 & 0 & 0 & 0 & 0 \\
\hline Henan & 0.388 & 0.574 & 0.676 & dec & 4493.01 & 8.63 & 555.39 & 0 & 0 & 50.2 \\
\hline Hubei & 0.387 & 0.558 & 0.693 & dec & 5459.55 & 17.68 & 0 & 22.65 & 0 & 22.51 \\
\hline Hunan & 0.247 & 0.265 & 0.931 & dec & 4649.4 & 8.44 & 18.06 & 0 & 0 & 0 \\
\hline Guangdong & 0.634 & 1 & 0.634 & dec & 0 & 0 & 0 & 0 & 0 & 0 \\
\hline Guangxi & 0.949 & 1 & 0.949 & dec & 0 & 0 & 0 & 0 & 0 & 0 \\
\hline Hainan & 1 & 1 & 1 & con & 0 & 0 & 0 & 0 & 0 & 0 \\
\hline Chongqing & 0.428 & 0.451 & 0.949 & dec & 1355.47 & 3.71 & 123.71 & 1.01 & 0 & 2.69 \\
\hline
\end{tabular}


Table 2. contd...

\begin{tabular}{|c|c|c|c|c|c|c|c|c|c|c|}
\hline \multirow{2}{*}{ Provinces } & \multirow{2}{*}{ CSE } & \multirow{2}{*}{ CRS } & \multirow{2}{*}{ SE } & \multirow{2}{*}{ RTS } & \multicolumn{2}{|c|}{ Input Redundancy } & \multicolumn{4}{|c|}{ Output Deficiency } \\
\hline & & & & & RDP & IEST & SPI & PST & NPA & NIS \\
\hline Sichuan & 0.233 & 0.373 & 0.625 & $\operatorname{dec}$ & 11459.66 & 65.74 & 0 & 69.82 & 15.38 & 0 \\
\hline Guizhou & 0.645 & 0.675 & 0.955 & dec & 702.79 & 1.2 & 0 & 14.86 & 65.85 & 0.08 \\
\hline Yunnan & 0.416 & 0.481 & 0.864 & $\operatorname{dec}$ & 2399.26 & 7.28 & 0 & 0 & 68.49 & 31.18 \\
\hline Shaanxi & 0.256 & 0.375 & 0.683 & $\operatorname{dec}$ & 15461.57 & 63.14 & 2335.93 & 146.11 & 0 & 98.46 \\
\hline Gansu & 0.805 & 1 & 0.805 & $\operatorname{dec}$ & 0 & 0 & 0 & 0 & 0 & 0 \\
\hline Qinghai & 0.947 & 0.992 & 0.955 & inc & 89.7 & 0.01 & 0 & 0 & 13.87 & 0 \\
\hline Ningxia & 1 & 1 & 1 & con & 0 & 0 & 0 & 0 & 0 & 0 \\
\hline Xinjiang & 1 & 1 & 1 & con & 0 & 0 & 0 & 0 & 0 & 0 \\
\hline
\end{tabular}

Notes: CES , CRS , SES ,RTS , dec , inc con, respectively, denotes" Comprehensive Efficiency Score", "Technical Efficiency Score”, "Scale Efficiency Score”, "Returns To Scale", "decreasing", "increasing" , "constant" . RDP, IEST, SPI, PST, NPA, NIS, respectively, denotes "R\&D Personnel (person)", "Intramural Expenditure on R\&D (RMB one hundred million)", "Scientific Papers Issued (piece)", "Publication on Science and Technology (kind)", "Number of Patent Applications Accepted (piece)", "National or industry standards (term)"

\subsection{Analysis of the Comprehensive Efficiency}

According to Table 2, the average efficiency score of R\&D input and output from R\&D Institutions in 30 provinces is 0.574 , so 30 provinces can be divided into three classes.

The first class, areas with high efficiency of R\&D input and output $(\theta=1)$ are: Hainan, Ningxia and Xinjiang, accounting for $10 \%$ of the overall. All the technical efficiency and scale efficiency of R\&D input and output is 1 , whose returns to scale are constant. Which shows that this kind of regional $R \& D$ Institutions continue to increase investment in $R \& D$, at the same time, should be pay more attention to rational allocation of resources, and the use of structural optimization [10-12].

The second class, areas with general efficiency of R\&D input and output $(0.574 \leq \theta<1)$ are: Guangxi, Qinghai, Gansu, Guizhou, Fujian, Zhejiang, Guangdong, Shanxi, Shandong, Jilin, Liaoning and Beijing, accounting for $40 \%$ of the all provinces. In these regions, the technical efficiency score of $R \& D$ input and output are higher than scale efficiency score except Guizhou, which shows that efficiency due to management and technology is much higher than the one from $R \& D$ scale. In the returns to scale, the provinces (except Qinghai) have characteristics of decreasing returns to scale, an unreasonable structure of R\&D input, and uneconomical use of resources have bigger influence on the R\&D efficiency $[13,14]$.

The third class, areas with poor efficiency of the R\&D input and output $(\theta<0.574)$ are: Shanghai, Jiangsu, Chongqing, Yunnan, Tianjin, Henan, Jiangxi, Hubei, Anhui, Heilongjiang, Inner Mongolia, Hebei, Shaanxi, Hunan and Sichuan, accounting for $50 \%$ of all provinces. In these regions (except Shanghai and Jiangsu), the technical efficiency is lower than scale efficiency, that is to say the efficiency of management and technology is lower than the one from scale expansion. In the returns to scale, the provinces (except Inner
Mongolia) have characteristics of decreasing returns to scale, an unreasonable structure of $\mathrm{R} \& \mathrm{D}$ input, and resources waste [15].

\subsection{The Analysis of the Input Redundancy and Output Deficiency}

According to calculation results of R\&D input redundancy and output deficiency from the national R\&D Institutions (Table 2), 30 provinces are divided into two types.

First, regions without input redundancy and output deficiency are: Beijing, Liaoning, Zhejiang, Fujian, Shandong, Guangdong, Guangxi, Hainan, Gansu, Ningxia and Xinjiang, accounting for $36.67 \%$ of all provinces. In these provinces, R\&D output and input of R\&D Institutions keeps the use of resources relative equilibrium.

Second, regions with input redundancy and output deficiency are: Tianjin, Hebei, Shanxi, Inner Mongolia, Jilin, Heilongjiang, Shanghai, Jiangsu, Anhui, Jiangxi, Henan, Hubei, Hunan, Chongqing, Sichuan, Guizhou, Yunnan, Shaanxi and Qinghai, accounting for $63.33 \%$ of all provinces. In these provinces, there are different levels of input redundancy and output deficiency.

From the input redundancy, there is one province whose R\&D personnel redundancy rate lower than $10 \%$-Shanghai; 2 provinces in 10\% 20\% - Jilin and Qinghai; 3 provinces in $20 \% \sim 30 \%$ - Shanxi, Jiangsu and Guizhou; 4 provinces in $30 \% \sim 40 \%$ - Tanjin, Henan, Chongqing and Yunnan; 9 provinces higher than $40 \%$ - Hubei, Hebei, Inner Mongolia, Heilongjiang, Anhui, Jiangxi, Hunan, Sichuan and Shaanxi. There are 2 provinces with R\&D expenditures redundancy rate lower than 10\% - Qinghai and Shanghai; 2 provinces in $10 \% \sim 20 \%$-Shanxi and Jilin; 2 provinces in $20 \% \sim 30 \%-$ Tianjin and Jiangsu; 1 province in 30\% 40\% -Henan; 12 provinces higher than $40 \%$ - Hebei, Inner Mongolia, Heilongjiang, Anhui, Jiangxi, Hubei, Hunan, Chongqing, 
Sichuan, Guizhou, Yunnan, Shaanxi. Which shows that nearly half of 19 provinces with inputs redundancy have problems of low efficiency and the R\&D Institutions overstaffed $[16,17]$.

From the insufficient output, there are 8 provinces with lack of science and technology papers published- Tianjin, Shanghai, Jiangsu, Shanxi, Henan, Hunan, Chongqing and Yunnan, including 2 with the serious shortage -Shanghai and Shaanxi; 11 provinces with lack of science and technology works -Hebei, Jilin, Shanghai, Jiangsu, Anhui, Jiangxi, Hubei, Chongqing, Sichuan, Guizhou and Shaanxi, including 6 with the serious shortage - Hebei, Shanghai, Jiangsu, Anhui, Sichuan and Shaanxi; 7 provinces with lack of patent application - Tianjin, Inner Mongolia, Heilongjiang, Jiangxi, Sichuan, Guizhou and Yunnan, including 3 with the serious shortage - Inner Mongolia, Jiangxi and Guizhou; 15 provinces with insufficient in forming national or industry standards - Hebei, Shanxi, Inner Mongolia, Jilin, Heilongjiang, Shanghai, Jiangsu, Anhui, Jiangxi, Henan, Hubei, Chongqing, Guizhou, Yunnan and Shaanxi, including 10 with the serious shortage- Shanxi, Inner Mongolia, Jilin, Heilongjiang, Shanghai, Jiangsu, Jiangxi, Henan, Yunnan and Shaanxi. Which shows that in $R \& D$ activities of national R\&D Institutions, there are a large number of high-quality science and technology papers published and patent applications accepted; while the amount of science and technology works and national or industry standards formed is relatively insufficient $[18,19]$.

\section{CONCLUSION AND RECOMMENDATIONS}

By the analysis of DEA efficiency on R\&D input and output of 30 provinces' R\&D Institutions in 2010, we can get the regional characteristics of $R \& D$ activities:

On the whole, the efficiency of R\&D input and output from national $R \& D$ Institutions is not high $(\theta=0.574)$, and the phenomena of excess input is very serious. The comprehensive DEA efficiency of R\&D Institutions from half of the overall is lower than the national average; the problem of R\&D input redundancy is serious, and $63.33 \%$ of provincial R\&D Institutions have different levels of R\&D input redundancy. This notes that, there exist serious problems of low innovation initiative and enthusiasm of R\&D personnel, unreasonable structure of the innovative input, resource waste, poor innovation continuity, and the shortage of high levels of achievement.

In the regional distribution, the efficiency of $R \& D$ input and output of the national R\&D Institutions does not adapt to their scales. Among 30 provinces, there are 5 provinces with a large proportion of $R \& D$ personnel of $R \& D$ Institutions Beijing, Shaanxi, Sichuan, Shanghai and Jiangsu, including Beijing belonging to areas with general comprehensive efficiency from the second class, and others belonging to areas with poor comprehensive efficiency from the third class; 10 with a large proportion of $R \& D$ personnel of R\&D Institutions - Liaoning, Henan, Shandong, Hubei, Hunan and Guangdong, Jilin, Heilongjiang, Tianjin and Gansu, including Liaoning, Shandong, Guangdong, Jilin, and Gansu belonging to areas with general comprehensive efficiency from the second class, and others belonging to areas with poor comprehensive efficiency from the third class; 15 provinces with a low proportion of R\&D personnel of R\&D Institutions - Hebei, Shanxi, Yunnan, Anhui, Zhejiang, Jiangxi, Guangxi, Inner Mongolia, Fujian, Guizhou, Hainan, Chongqing, Xinjiang, Qinghai and Ningxia, including Xinjiang, Hainan and Ningxia belonging to areas with high comprehensive efficiency from the first class, and Shanxi, Zhejiang, Guangxi, Fujian, Guizhou and Qinghai belonging to areas with general comprehensive efficiency from the second class, and the others belonging to areas with poor comprehensive efficiency from the third class. This shows that good regions with good R\&D foundation and a large-scale R\&D resources have serious problems of waste and low efficiency of utilization of resources in China; while bad regions with weak R\&D foundation have a relatively high efficiency.

In $R \& D$ activities carried out, regional $R \& D$ Institutions should adjust measures to improve the efficiency of input and output, according to the characteristics of their R\&D activities. The first class, R\&D Institutions located in provinces with high comprehensive efficiency and constant returns to scale, should continue to increase the intensity of $R \& D$ investment, optimize the structure of $R \& D$ resources utilization, and realize the stable promotion of the scale and structure of R\&D efficiency, and rapidly improve their R\&D competitiveness. The second class, R\&D Institutions located in provinces with the general comprehensive efficiency and increasing return to scale, should focus on increasing R\&D investment, expanding the scale of R\&D. Provinces with decreasing returns to scale, must control the $R \& D$ input speed of expansion, strengthen the management of $R \& D$ resources, adjust and optimize the structure of personnel and funds input, strengthen the supervision and evaluation of the R\&D process, and improve the utilization efficiency of resources. The third class, R\&D Institutions located in provinces with poor overall efficiency and decreasing returns to scale, should slow down the growth of $R \& D$ resources input, find out some drawbacks in R\&D activities as soon as possible, and solve them, and also careful analysis, formulate specific measures of improving the efficiency of R\&D different situation, according to the $\mathrm{R} \& \mathrm{D}$ resources or excess demand.

\section{CONFLICT OF INTEREST}

The authors confirm that this article content has no conflict of interest.

\section{ACKNOWLEDGEMENTS}

We are grateful to anonymous referees and the handling editor for helpful comments and suggestions. The financial supports from Hebei province Natural Science Foundation of (G2012208057) and Hebei province Soft Science Plan Funded Project of (134576122D), are also gratefully acknowledged.

\section{REFERENCES}

[1] Z. Hao, and M. Xianzhong, "DEA Evaluation and Comparison of R\&D Efficiency among Different Organization,” pp.78-82, 12, 2005

[2] R. Li, J. Wu, and H. Cui, "Evaluation and Analysis to Regional Enterprise Technology Innovation Effectiveness Based on DEA," 
International Conference on Machine Learning and Cybernetics, pp. 2543-2548, 2009.

[3] W.Liuyi, "Analysis of R\&D Input and Output of Guangdong Research Institutes," Journal of Guangdong Institute of Public Administration, pp. 73-78, 2012

[4] W. Zhiyong and H. Zhouyong, "The DEA analysis of efficiency of input and output of r\&d performer of heilongjiang province," Science \& Technology Ecnony Market, pp. 331-332, 2007.

[5] H. Zhaozhou,W. Binhui, L. Weilin and S. Shaoyong, "Efficiency research of R\&D input and output," Statistics and Forecasting, pp. $17-20,2003$

[6] Hongzhuan, and S. Liangliang, "Measuring the efficiency of China's high-tech industrial park by DEA Model," Science of Science and Management of S. \& T, pp.104-109, 2013.

[7] W. Xiaozhen, J.I. Shengbao, C.U.I. Xinjian, and S.H.I. Ruyi, "Research on R\&D efficiency evaluation and resource allocation based on DEA Cross-efficiency-example of regional high-tech industry", Science and Technology Management Research, pp.115-120, 2012.

[8] M. Oral, O. Kettani, P. Lang. "A methodology for collective evaluation and selection of industrial R\&D Projects," Management Science, pp. 871-883, 1991.

[9] J. Doyle, R. Green, and W.D. Cook, "Preference voting and project tranking using DEA and cross-evaluation," European Journal of Operational Research, vol. 90, pp. 461-472, 1996.

[10] Wu Yun, "Impact of governmental investment on Science \& Technology Innovation: empirical test based on panel data of 40 countries from 1982 to 2010," Science of Science and Management of S. \& T., vol. 35, pp. 16-21, 2014.
[11] X. Qiaoling, "Efficiency evaluation on science and technology input and output - based on DEA - the BCC model and SE CCR model," Science and Technology Management Research, pp. 66-70, 2014.

[12] L. Yuedong, S. Yuan, and D. Zhongxian, "Evaluation on provincial financial science and technology input-output performance in China", Journal of Dialectics Of Nature, vol.35, pp.88-95, 2013.

[13] F. Xing, M. Shucai and Z. Lianzhou, "Comparative analysis of science and technology activities input and output efficiency" Science and Technology Management Research, pp.79-83, 2013.

[14] H. Enhua, L.Ong, and Z. Long, "An empirical analysis of economic effectss of Chinese science and technology investment", Science Research Management, vol. 4, pp. 71-75, 2004.

[15] W. Hecheng, and Z. Chuiyong, "An empirical analysis on the relative efficiency of the input - output of science and technology", Scientific Management Research, vol. 3, pp. 93-96, 2003.

[16] Yanhua, and Y. Shu, "The international comparison and suggestions of investment in science and technology of developed country and china", Science and Technology Management Research, vol. 24, pp. 21-24, 2012.

[17] S. Yutao, L. Fengchao, and X. Qian,"Analysis on the structure evolution of science and technology input in China's eight major economic regions based on the specialization coefficient", Management Review, vol. 2, pp. 80-86, 2011

[18] S. Yinqiu, "Study on the Rationality of structure for R\&D expenditure", Statistical Research, vol. 26, pp. 53-55, 2009.

[19] S. Yinqiu, L. Ping and H. Wen, "The structure comparison of Sino -US R\&D expenditure", Science Research Management, vol. 4, pp. 102-107, 2012.

(C) Li et al.; Licensee Bentham Open.

This is an open access article licensed under the terms of the Creative Commons Attribution Non-Commercial License (http://creativecommons.org/licenses/by-nc/3.0/) which permits unrestricted, non-commercial use, distribution and reproduction in any medium, provided the work is properly cited. 